EGU2020-11590

https://doi.org/10.5194/egusphere-egu2020-11590

EGU General Assembly 2020

(c) Author(s) 2021. This work is distributed under

the Creative Commons Attribution 4.0 License.

\title{
A plea for a novel kind of ecohydrology: the interaction between hydrological processes and - endangered or not - wildlife
}

\author{
Jasper Griffioen ${ }^{1,2}$, Martin Wassen ${ }^{2}$, and Joris Cromsigt ${ }^{2,3,4}$ \\ ${ }^{1}$ TNO Geological Survey of the Netherlands, geo-modelling, Utrecht, Netherlands (jasper.griffioen@tno.nl) \\ ${ }^{2}$ Copernicus Insitute of Sustainable Development, Utrecht University, Utrecht, the Netherlands (j.griffioen@uu.nl) \\ ${ }^{3}$ Department of Wildlife, Fish and Environmental Studies, Swedish University of Agricultural Sciences, Umea 901 83, Sweden \\ ${ }^{4}$ Centre for African Conservation Ecology, Department of Zoology, Nelson Mandela University, PO Box 77000, Port Elizabeth \\ 6031, South Africa
}

Ecohydrology usually refers to the effects of hydrological processes on the occurrence, distribution and patterns of plants. Here, we emphasize a new kind of ecohydrology in which the effects of hydrological processes on the occurrence of - endangered or not - wildlife become addressed via the threat of its habitat or, oppositely, where the occurrence of wildlife leads to a threat of endangered fauna. We present three examples to illustrate this.

First, the habitat of the tiger in the Terai Arc Landscape (TAL) at the foot of the Himalayas seems to increasingly become threatened by changes in the hydrological conditions. Grasslands in floodplains are an important part of the tiger habitat as these are the grounds where the tiger preferably hunts for deer as his prey. Disturbances of the water systems such as gravel and sand extraction from the river beds, intake of water for irrigation and hydropower production are increasingly happening and climate change may further alter the Himalayan water systems. This seems to disturb the grasslands in their hydrological and hydromorphological dynamics, which may negatively impact the density of deer, which may put additional pressure on the tiger populations in the nature reserves of the TAL.

Second, ungulates are important mammals in the grasslands and savannah of southern Africa. The water availability for these animals may alter upon climate change, including higher frequencies of droughts. Research suggests that the community composition of ungulates may alter by this. Here, the larger water-dependent grazers may be replaced by smaller, less waterdependent species.

Third, the beaver is well-known as hydrological ecosystem engineer. The beaver, therefore, has obtained some attention within the context of ecohydrology. The impact of the beaver as ecosystem engineer is, however, peculiar for nature reserves at the Belgian-Dutch border. Surface water with poor quality due to lack of appropriate sewage water treatment is running along nature reserves. The reintroduction of the beaver causes a rise in the surface and groundwater levels due to its dam-building activities. This induces an introduction of polluted surface water into the Dutch wetlands which contain a less eutrofied ecosystem than the Belgian ones that were fed by the 
polluted surface water. Nature restoration may thus go on the expense of nature degradation.

These examples show that the ecohydrology of wildlife is as fascinating and diverse as classical ecohydrology is. 